\title{
Changing Surgical Antimicrobial Prophylaxis Practices through Education Targeted at Senior Department Leaders
}

\section{Citation}

Everitt, Daniel E., Stephen B. Soumerai, Jerry Avorn, Henry Klapholz, and Michael Wessels. 1990. "Changing Surgical Antimicrobial Prophylaxis Practices through Education Targeted at Senior Department Leaders." Infection Control and Hospital Epidemiology 11 (11) (November): 578-583. doi:10.1086/646098.

\section{Published Version}

doi:doi.org/10.1086/646098

\section{Permanent link}

http://nrs.harvard.edu/urn-3:HUL.InstRepos:32696180

\section{Terms of Use}

This article was downloaded from Harvard University's DASH repository, and is made available under the terms and conditions applicable to Other Posted Material, as set forth at http:// nrs.harvard.edu/urn-3:HUL.InstRepos:dash.current.terms-of-use\#LAA

\section{Share Your Story}

The Harvard community has made this article openly available.

Please share how this access benefits you. Submit a story.

Accessibility 


\title{
Changing Surgical Antimicrobial Prophylaxis Practices Through Education Targeted at Senior Department Leaders
}

\author{
Daniel E. Everitt, MD; Stephen B. Soumerai, ScD; Jerry Avorn, MD; \\ Henry Klapholz, MD; Michael Wessels, MD
}

\begin{abstract}
Prescribing antibiotics for perioperative prophylaxis in common surgical procedures presents an ideal target for educational intervention. In this situation, antibiotics are often used inappropriately, with consequent excess expense and risk of morbidity. We developed an educational intervention aimed at the choice and appropriate dosing of antibiotics for the prophylaxis of cesarean sections. Person-to-person educational messages targeted at authoritative senior department members were supplemented by brief reminders on a structured antibiotic order form. Time-series analyses were conducted on 34 months of antibiotic use data for 2,783 cesarean sections to estimate the trend of magnitude and significance of discontinui-
\end{abstract}

From the Program for the Analysis of Clinical Strategies, Harvard Medical School (Drs. Everitt, Soumerai and Avorn); the Department of Medicine, Beth Israel Hospital (Drs. Everitt and Wessels); the Geriatric Research, Education and Clinical Center, Brockton/W. Roxbury Veterans' Administration Medical Center (Dr. Everitt); and the Division of Maternal Fetal Medicine, Department of Obstetrics and Gynecology, Beth Israel Hospital (Dr. Klapholz), Boston, Massachusetts.

This work was supported by the Beth Israel Hospital, Boston, Massachusetts, and by a grant from the Fund for Cooperative Innovation of Blue Cross of Massachusetts and the Massachusetts Hospital Association.

The authors are grateful for the help of Jeremy Nobel, MD, and Ira Tager, $M D$, in the development and analysis of the intervention; to Charles Safran, MD, and colleagues in the Harvard Center for Clinical Computing for use of the "Patient Chase" data base; to Richard Platt, MD, for data on the choice of prophylactic antibiotics at the Brigham and Womens Hospital, Boston, Massachusetts; and to Susanne Bellavance and Sharon Hawley for preparation of the data and the manuscript.

Address reprint requests to Daniel E. Everitt, MD, Program for the Analysis of Clinical Strategies, 3rd Floor, 333 Longwood Avenue, Boston, MA 02115.

Everitt DE, Soumerai SB, Avorn J, Klapholz H, Wessels $M$. Changing surgical antimicrobial prophylaxis practices through education targeted at senior department leaders. Infect Control Hosp Epidemiol. 1990;11:578-583. ties associated with the start of the program. Prior to the intervention, 95\% of sections receiving prophylaxis were given cefoxitin and $3 \%$ were given cefazolin. After the intervention, these proportions were reversed, with the shift in use occurring immediately after the intervention $(p<.001)$. Two years after the intervention, virtually all patients undergoing cesarean sections who receive antibiotic prophylaxis are given cefazolin. Savings from this change alone accounted for over $\$ 26,000$ each year, or $\$ 47.36$ per patientday of prophylaxis. Substantial changes in prescribing practices for routine procedures can be accomplished through the implementation of a coordinated educational program that enlists influential senior staff members in a department in which policy-making is highly centralized, coupled with a structured educational ordering system. Lasting improvements in clinical practices may be brought about by means that are noncoercive, inexpensive and well-accepted by medical staff. (Infect Control Hosp Epidemiol. 1990;11:578-583.)

\section{INTRODUCTION}

Prescribing practices vary considerably for antibiotics in widespread use in the hospital setting. In most hospitals, antibiotics constitute the costliest drug category. New, very expensive antimicrobial agents are often promoted for particular uses without evidence from well-controlled clinical trials to demonstrate their superiority over older, less expensive agents. Considerable evidence exists that much in-hospital antibiotic use is not in keeping with available data from randomized controlled trials. This is true of both prophylactic and therapeutic antimicrobial therapy. ${ }^{1}$

The routine use of antibiotics for prophylaxis during surgical procedures represents an ideal area for interventions aimed at reducing hospital costs while improving the rationality of care. A number of audits of practice in large hospitals have identified substantial inappropriate use of antibiot- 
ics in the perioperative setting. ${ }^{1,2}$ The president of the Joint Commission on Accreditation of Healthcare Organizations (JCAHO) has noted that "the ongoing review of antibiotic usage (was) the most common source of noncompliance with the standards. Failure to take action based on findings from antibiotic usage review was another common source of noncompliance." 2

Once practice deficiencies have been identified, bringing about change in daily practice may be quite difficult. Yet, such changes in procedures that may be repeated hundreds of times in a year can translate into marked clinical impact and cost savings. In many cases of antimicrobial prophylaxis, clear recommended standards may be identified. Furthermore, the methods used to improve prescribing practices for one procedure or for one category of antibiotic may be easily transferable to other similar situations.

Studies of systematic efforts to change prescribing practices in the hospital have been increasing and take a variety of approaches. Restrictive approaches have been in use for years, such as the use of hospital formularies. Relatively restrictive practices, such as requiring a consultation for the use of particular drugs, are in place in many hospitals and are often used for prescribing certain antibiotics. When these programs have been studied, in general, the prescription of the restricted drugs immediately began to rise to preintervention levels once restrictions were lifted. , $^{3,4}$

Two studies have shown that an administrative intervention can change antibiotic prescribing for surgical prophylaxis. Durbin, et al. required physicians to categorize the reason for antibiotics on a preprinted order form; antibiotics ordered for prophylaxis were automatically discontinued after 48 hours. ${ }^{5}$ Similarly, Echols and Kowalsky had ordering physicians categorize the indications for antibiotics at the time of ordering, and those for prophylaxis were automatically discontinued. ${ }^{6}$ Both of these intervention were relatively effective, although neither was aimed at changing the choice of specific antibiotic, and neither relied on an educational approach.

The dissemination of printed drug information and the education of groups through lectures or rounds have been shown to have some important short-term effects, but the effects of such educational efforts often quickly deteriorate as well. ${ }^{7}$ Two large studies aimed at prescribing in the ambulatory setting have shown that one-on-one face-to-face educational programs can effect lasting changes that are far greater than printed material or group interactions alone. ${ }^{8,9}$

In a comprehensive review of physician decisionmaking, Eisenberg underscored the important role of professional leadership in effective education. ${ }^{10}$ In one program of continuing education at a community hospital in California, hospital-wide im- provements in targeted prescribing practices were attributed to the personal involvement of highly regarded faculty. ${ }^{11}$ A physician's professional environment and the role of professional leadership have been shown by a number of studies to be critical determinants of practice patterns, and particulary of the use of antibiotics. ${ }^{12-14}$

We identified antimicrobial prophylaxis for surgical procedures in general, and cesarean sections in particular, as ideal targets of an educational program. In this study, we made use of a highly centralized department of obstetrics and gynecology with influential senior staff. We avoided a restrictive approach and combined several of the most effective methods of behavior change within a specific institutional context. This experience provided an example that may be generalizable to other institutions attempting to improve the efficiency of prophylactic antibiotic use.

\section{METHODS}

We began by performing an audit to characterize the use of perioperative antibiotics for all surgical procedures at the Beth Israel Hospital, Boston, Massachusetts, for a two-week time period, using an audit instrument developed in collaboration with the staff of the hospital's quality assurance department. All surgical procedures were identified through the use of operating room schedules. Quality assurance staff reviewed all charts after discharge to collect demographic data, including patient age, gender, diagnosis and procedure, dates of admission and discharge, surgeon of record and the presence of conditions such as diabetes, cancer or concurrent chemotherapy. For all patients who received perioperative antibiotics, the following data were collected: occurrence of antibiotic administration within three days prior to surgery; surgical date and time; time of first dose and subsequent doses of antibiotics; name of antibiotic; dosing interval ordered; duration ordered immediately postoperatively; and actual date and time of discontinuation of antibiotics. These data made it possible to distinguish between antibiotics intended as prophylactic and those initiated or continued for documented infection.

During months 1 and 2, informal open-ended interviews were held with house officers on the obstetrics and gynecology service to determine their beliefs and practices in relation to the use of antimicrobial prophylaxis, as well as perceived sources of information and authority on the subject. During weeks 10 through 13, an extensive literature search was made on the appropriate use of prophylactic antibiotics for cesarean section and hysterectomy. Using this information, the authors drafted a two-page teaching monograph with summary recommendations for members of the department of obstetrics and gynecology. The summary recommendations for cesarean section were: "Pa- 


\begin{tabular}{|c|c|c|}
\hline \multicolumn{3}{|c|}{$\begin{array}{l}\text { Table } \\
\text { Cesarean Section Prophylaxis Practices from } \\
\text { Chart Audits }\end{array}$} \\
\hline & $\begin{array}{l}\text { Month } 19 \\
\text { Audit } \\
\text { No. }(\%) \\
\end{array}$ & $\begin{array}{l}\text { Month } 25 \\
\text { Audit } \\
\text { No. }(\%) \\
\end{array}$ \\
\hline Total cesarean sections* & 30 & 23 \\
\hline Elective & $10(33)$ & $3(13)$ \\
\hline Emergency & $20(67)$ & $20(87)$ \\
\hline Elective procedures with prophylaxis & $2(20)$ & $1(33)$ \\
\hline $\begin{array}{l}\text { Emergency procedures with antibiotics } \\
\text { (Month } 25 \text { includes five with } \\
\text { antibiotics given for apparent } \\
\text { infection) }\end{array}$ & $20(100)$ & $17(85)$ \\
\hline $\begin{array}{l}\text { Total cesarean sections with } \\
\text { prophylaxis dosing } \dagger\end{array}$ & 22 & 13 \\
\hline Single dose & $2(9)$ & $0(0)$ \\
\hline$\leqslant 24$ hours & $17(77)$ & 10 \\
\hline$>24$ hours & $3(14)$ & 3 \\
\hline Prophylaxis with cefazolin & $16(73)$ & $11(85)$ \\
\hline Cefoxitin & $4(18)$ & $2(15)$ \\
\hline Other & $2(9)$ & $0(0)$ \\
\hline \multicolumn{3}{|c|}{$\begin{array}{l}\text { * Represents a random one-third of all cesarean sections performed during } \\
\text { the month } \\
+ \text { Includes cases with antibiotic beginning at surgery and lasting } 48 \text { hours. } \\
\text { All longer dosing periods were cases with evidence of infection. }\end{array}$} \\
\hline
\end{tabular}

tients with risk factors (defined earlier) or emergency cesarean section: A single dose of cefazolin (Ancef, Kefzol), $1 \mathrm{~g}$ to $2 \mathrm{~g}$ intravenously, after clamping of cord, should suffice. If more than one dose is given, give no more than three doses eight hours apart. Routine elective cesarean section: Indications for prophylaxis not clear; if prophylaxis is given, a single dose of cefazolin is sufficient."

These recommendations were based on the best available trials in the medical literature, as well as an understanding of current practices in our institution, and a sensitivity to the preferences of senior department staff in situations where studies have been inconclusive. Consensus was strong in the literature that a first-generation cephalosporin should be the drug of choice, and that expensive second- and third-generation cephalosporins offer no advantage.$^{15}$ One adequately designed randomized controlled trial compared cefazolin with cefoxitin in patients undergoing nonelective cesarean section. ${ }^{16}$ In this trial, there was no difference in the rates of genital tract-related infection between the two drugs (about $6 \%$ of 243 patients). Studies also have shown clearly that prophylactic antibiotics should not be given for longer than 24 hours. ${ }^{17,18}$ Although it is likely that a single dose of antibiotic is adequate ${ }^{15}$ this has not been shown conclusively.

The intervention began when a description of the hospital's Drug Information Program and a copy of the teaching monograph were circulated to key department leaders during months 13 and 14 of the project. These leaders included the chief of the department of obstetrics and gynecology, the assistant director of the division of maternal fetal medicine, the director of the pharmacy and the hospital epidemiologist. These leaders were asked for critical comments and suggestions, with the plans that this information would be disseminated more widely and formally. The recommendations were then reviewed in detail with these clinicians.

During month 13, a new structured intravenous antibiotic order form was put into place by the authors. ${ }^{19}$ The form contained several educational messages about appropriate antibiotic use, including a reminder that cefazolin should be given no more frequently than every eight hours; however no particular mention was made of the perioperative use of antibiotics.

During months 19 (six months following the teaching targeted at department leaders) and 25, followup audits were made by quality assurance department staff similar to the audit described above. However, only cesarean sections were reviewed; a random one-third of the procedures for the entire month were audited. In addition to the data noted above, information was noted as to whether the section was routine elective or emergency. The reasons for emergency sections were recorded.

Finally, a retrospective audit was made of all perioperative cephalosporin use in cesarean sections for each of the 34 months of the study using the hospital's relational data base that collects data from numerous sources, including medical records, pharmacy and the clinical laboratories. All patients with DRG 371 (routine cesarean section) or DRG 370 (cesarean section with complication) were identified separately. Those considered to have received prophylactic doses (as validated from the other audits) included patients who received up to and including $5 \mathrm{~g}$ of either cefazolin or cefoxitin.

Statistical analysis used information aggregated for 34 separate four-week periods, starting ten months prior to the targeted education and introduction of the structured order form and ending 20 months after this intervention. The unit of analysis was the proportion of cesarean cases receiving either cefoxitin or cefazolin relative to the total number of cesarean cases receiving one of these two drugs. Interrupted time-series analysis was used to study changes in prescribing that occurred at the time the program was introduced. Segmented regression models were fit that assessed whether there were significant changes in trends for each drug at the point of intervention. ${ }^{20}$ Two-tailed $t$-tests were used to estimate the statistical significance of estimated changes in levels or trends. Coefficients with statistically insignificant effects $(p>.05)$ were dropped in a step-down manner. Costs to the pharmacy for all study drugs were measured for the study period. 


\section{RESULTS}

Interviews with house officers on the obstetrics and gynecology service identified several commonly held beliefs and practices. Many of these residents identified cefoxitin as the drug commonly used for antimicrobial prophylaxis in cesarean sections, because of a perceived advantage over first-generation cephalosporins in coverage of anaerobic bacteria that colonize the pelvic area. Regarding the use of prophylactic antibiotics, residents reported that the antibiotics were uniformly given just after clamping the umbilical cord, and were usually given for a 24-hour period after surgery.

The preliminary audit of practices for cesarean sections confirmed some of what was learned in the interviews. The random sample of sections done in month 1 of the study showed that only two of ten routine cesarean sections received no prophylaxis; the eight that did receive prophylaxis received cefoxitin perioperatively. Five of the eight had prophylactic antibiotics continued longer than 24 hours, although none were continued longer than 48 hours.

This information allowed a more specific targeting of educational material designed to bring practice to conformity with the literature on the subject. Summary recommendations were focused on two areas: cefazolin was recommended as the antibiotic of choice; and if antibiotics were given for prophylaxis for more than one dose, they were not to be given longer than 24 hours. Proper dosing of cefazolin at eight-hour intervals was reinforced through the antibiotic order form that was put into use during month 13 of the project.

As a result of the educational material presented to senior departmental leaders, the department of obstetrics and gynecology put in place several subsequent educational interventions aimed at bringing practice in line with our recommendations. The guidelines were discussed in several conferences and grand rounds with house staff and attending staff. These department leaders subsequently changed the stocking of the operating rooms in the labor and delivery area to cefazolin, and the cefoxitin that had been available previously was removed from the supply shelf, although it continued to be available from the pharmacy. Obstetrics staff could order the antibiotic of their choice at any time, but the choice of cefazolin was clearly more convenient. Results of the subsequent audits were so encouraging that it became unnecessary to follow through with the original plans for further dissemination of the educational materials. By the end of the second audit in month 19 of the study, only two of ten patients undergoing elective cesarean sections received any prophylaxis, whereas all 20 emergency procedures received perioperative antibiotics. Two of 22 prophylactic courses were single doses; 17 of 22 were for a time

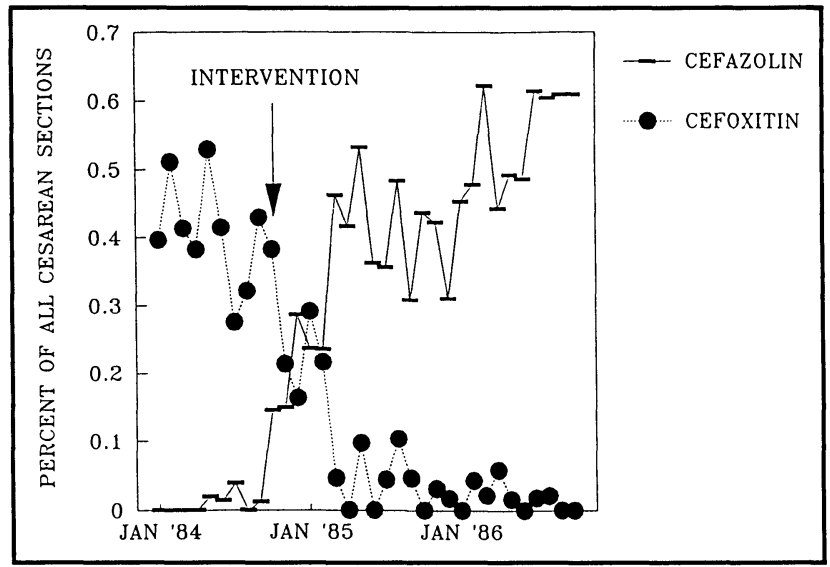

Figure. Proportion of all cesarean sections receiving $<5 \mathrm{~g}$ of cefazolin or cefoxitin perioperatively during a 34-month period.

period less than or equal to 24 hours, and only three doses extended beyond 24 hours. In this audit, 16 of 22 patients received cefazolin $(73 \%)$, four of 22 (18\%) received cefoxitin and two of 22 received other antibiotics.

The third audit took place in month 25,12 months after the targeted educational intervention. This audit had results similar to the second audit and is summarized in the Table. Of 20 emergency sections, three patients did not receive antibiotics. Of those receiving prophylactic antibiotics, none received a single dose, ten of 13 received dosing for less than or equal to 24 hours and three had courses longer than 24 hours (four cases appeared to receive antibiotics for infections). Eleven of $13(85 \%)$ prophylactic courses were for cefazolin and only two of $13(15 \%)$ were for cefoxitin.

A month-by-month computerized audit was then done of all cephalosporin use for cesarean sections during the study period to measure the magnitude and duration of the switch from cefoxitin to cefazolin. The hospital's relational data base ${ }^{21}$ was used to look at cefazolin and cefoxitin use by all patients discharged with DRG 370 or 371. Those cases considered to have received prophylaxis dosing were those receiving up to and including $5 \mathrm{~g}$ of the drug. The recommended dose was either a single $1 \mathrm{~g}$ or 2 $\mathrm{g}$ dose, or $1 \mathrm{~g}$ every eight hours for three doses.

Using this data base, we first determined that the proportion of all cesarean sections considered complicated (DRG 370) did not change significantly (29\% prior to the intervention, $27 \%$ following it). The fraction of all cesarean sections that received prophylaxis with $5 \mathrm{~g}$ or less of either cefoxitin or cefazolin also remained constant at $44 \%$. This percentage was not significantly different for "complicated" versus "uncomplicated" procedures.

The most remarkable change in practice was the switch from cefoxitin to cefazolin use at the time of the intervention. The Figure demonstrates the month-by-month use of the two cephalosporins. 
When prophylaxis was given, cefoxitin was the antibiotic used nearly $100 \%$ of the time before the intervention, and was essentially replaced by cefazolin after the intervention. This change in practice held constant for two years after the targeted education. Time-series regression analyses clearly indicated a significant change in trend coincident with the educational intervention. From the indepth audit, we know that a cephalosporin was used almost uniformly for routine prophylaxis; most instances of other drug use in the perioperative setting was in the face of documented or suspected infection and was not for routine prophylaxis.

The economic savings from this shift in antibiotic use were substantial in comparison to the modest costs of researching the clinical literature, holding several meetings with peer department leaders and including a reminder on the educational order form. During the last ten months of observation in 1986, 470 cesarean sections were performed with cefazolin prophylaxis, yielding an estimated annual rate of 564 cases that would have previously received cefoxitin. Based on our hospital's actual drug ingredient costs in 1986, the daily cost of cefoxitin was $\$ 47.36$ higher than that of cefazolin. Assuming conservatively that the average duration of therapy was 24 hours, the estimated yearly savings in drug ingredient costs alone was $\$ 26,711$. However, this figure does not take into account that cefoxitin is almost always administered four times a day, in contrast to cefazolin, which, because of its long half-life, is administered only three times a day. This added savings of material and labor (pharmacy and nursing) would increase the total estimated savings to approximately $\$ 28,000$ annually. Such potential savings assume that infection rates and hospital lengths of stay are the same for both regimens; any changes in these variables could substantially reduce or increase the cost savings of this intervention.

\section{DISCUSSION}

Recent reviews come to substantial consensus in their recommendations concerning antimicrobial prophylaxis in gynecologic surgery. We chose to focus on cesarean sections because they are a high-volume procedure for which clear recommendations may be made. These recommendations focused on an easily accepted therapy that was an alternative to the prevailing practice in our hospital.

Trials have generally shown that prophylaxis reduces endometritis and wound infection in emergency sections (e.g., membranes have ruptured) or in arrest of fetal descent in cephalopelvic disproportion. ${ }^{22,23}$ Randomized trials have been inconclusive on the benefits of prophylaxis in elective sections; thus, our recommendations focused on the proper choice and administration of antibiotic if one was used, and we chose to leave the decision of whether or not to use prophylaxis to the individual surgeon in this situation. The literature indicates that if prophylaxis is used, it should be administered immediately after clamping the umbilical cord. ${ }^{15}$ As noted previously, consensus is strong that a firstgeneration cephalosporin should be the drug of choice, and that the expensive second- and thirdgeneration cephalosporins offer no advantage. ${ }^{15,16}$

A number of techniques have been used to influence the use of antibiotics in the hospital setting. Restrictive or administrative approaches may work in the short-run, but by themselves have relatively little educational value , $^{8,9,24}$ Improvement in the use of prophylactic antibiotics for gynecologic surgury was noted by Achong, et al. in Canada. ${ }^{25}$ The only "intervention" in this case was the original survey of prescribing physicians; no data were available regarding the permanence of this unexpected change in practices. Required consultation by infectious disease consultants has been an effective tool, but it is expensive and cumbersome and may be seen by front line caretakers as intrusive. ${ }^{8}$ Audits with feedback of group performance are generally ineffective in changing practice; they may fulfill accreditation criteria but they rarely provoke lasting change. Similarly, printed educational material by itself rarely causes changes in practice. ${ }^{6}$ However, three approaches to effecting changes in practice patterns have been shown to be the most powerful: the education of prescribing physicians using face-to-face interactions ${ }^{8,9}$; the use of key opinion leaders ${ }^{10-12}$; and implementation of instantaneous reminders (as in a structured ordering system) to prevent prescribing errors before they occur. ${ }^{19}$ Indeed, these strategies have been found to be among the most powerful techniques used by pharmaceutical representatives who are remarkably successful at changing the prescribing behavior of individual physicians. ${ }^{26}$

We chose to direct our educational intervention to senior staff who we believed would be influential in a department known for fairly centralized policymaking. The background interviews with house staff and the initial audit helped identify the specific area in need of intervention, and helped focus our intervention. We approached these leaders with the relevant literature and feedback of current practices in their department, using prepared printed material and an ongoing dialogue. This effort was well received and set off a chain of behavior reinforcements and an administrative intervention; these leaders in turn conducted their own educational effort through appropriate departmental channels (conferences and grand rounds). Additionally, they changed the convenience by which the recommended antibiotic could be used. The concurrent use of a stuctured antibiotic order form did not specifically address the choice of perioperative antimicrobial agents. We did not 
expect much change in the total numbers of elective sections receiving prophylaxis or in the number receiving only one dose of antibiotic, as we allowed discretion in these areas.

The in-depth audits and the month-by-month time-series analysis presented above show substantial (over 85\%) compliance with the recommended changes in choice of antibiotic, dosing and maximum duration of administration of 24 hours. The results of clinical trials presented in the literature may have set the stage for the receptivity of obstetricians to our recommendations. However, the most directly relevant clinical trial that compared cefoxitin with cefazolin during cesarean section was published a full year before our intervention and observed changes. ${ }^{16}$ In addition, previous studies have reported that even printed consensus guidelines have been ineffective in changing practice related to cesarean sections. ${ }^{27}$

Our analysis did not include concurrent controls; however, the suddenness of the change observed at the time of the intervention makes it unlikely that the change was caused by factors other than the intervention, or that it was a random fluctuation in time (Figure). The stable use of cefoxitin for nine months before the intervention and the continued stable use of cefazolin for 18 months after the intervention also make it unlikely that this change was related to historical trends or to any specific reports in the literature. Additionally, the choice of antibiotics as prophylaxis for cesarean sections was stable from 1983 through 1987 at a teaching hospital across the street. Of patients receiving cephalosporins for this indication, the use of cefazolin ranged from $22 \%$ to $30 \%$, and cefoxitin use ranged from $96 \%$ to $78 \%$ during this time period (Richard Platt, MD, personal communication, 1990). The changes observed at our hospital lasted for over two years with a minimum of reinforcement, and have been well accepted. The specific recommendations will be amenable to periodic review and update. While this program was conducted in a teaching hospital department with relatively centralized policy making, this model may be applicable to other contexts in which "opinion leaders" are likely to have influence on policy and practice. ${ }^{28}$

\section{REFERENCES}

1. Shapiro M, Townsend TR, Rosner B, Kass E. Use of antimicrobial drugs in general hospitals. N Engl J Med. 1979;301:351-355.

2. Affeldt JE. Antibiotic use is source of deviance from standards. Hospitals. August 16, 1984:74.

3. McGowan JE, Finland M. Effects of monitoring the usage of antibiotics: an interhospital comparison. South Med J. 1976;69:193-195.

4. Craig WA, Uman SJ, Shaw WR, et al. Hospital use of antimicrobial drugs: survey at 19 hospitals and results of antimicrobial control program. Ann Intern Med. 1978;89:793-795.

5. Durbin WA, Lapidas B, Goldmann DA. Improved antibiotic usage following introduction of a novel prescription system. JAMA. 1981;246:1796-1800.

6. Echols RM, Kowalsky SF. The use of an antibiotic order form for antibiotic utilization review: influence on physicans' prescribing patterns. J Infect Dis. 1984;150:803-807.

7. May FE, Stewart RB, Cluff LE. Drug use in the hospital: evaluation of determinants. Clin Pharmacol Ther. 1974;16:834-845.

8. Avorn J, Soumerai SB. Improving drug-therapy decisions through educational outreach: a randomized controlled trial of academically based 'detailing.' N Engl J Med. 1983;308:1457-1461.

9. Schaffner W, Ray WA, Federspiel CF, Miller WO. Improving antibiotic prescribing in office practice: a controlled trial of three educational methods. JAMA. 1983;250:1728-1732.

10. Eisenberg JM. Doctors' Decisions and the Cost of Medical Care: The Reasons for Doctors' Practice Patterns and Ways to Change Them. Ann Arbor, Mich: Health Administration Press Perspectives; 1986.

11. Rubenstein E. Continuing medical education at Stanford: the backto-medical-school program. Journal of Medical Education. 1973;48:911-918.

12. Geertsma RH, Parker RC, Whitbourne SK. How physicians view the process of change in their practice behavior. Journal of Medical Education. 1982;57:752-761.

13. Thompson RS, Kirz HL, Gold RA. Changes in physician behavior and cost savings associated with organizational recommendations on the use of "routine" chest x-rays and multichannel blood tests. Prev Med. 1983;12:385-396.

14. Check WA. How to affect antibiotic prescribing practices. JAMA. 1980;244:2594-2595.

15. Antimicrobial prophylaxis in surgery. Med Lett Drugs Ther. 1987;29:91-94.

16. Stiver HG. Forward KR, Livingstone RA, et al. Multicenter comparison of cefoxitin versus cefazolin for prevention of infectious morbidity after nonelective cesarean section. Am J Obstet Gynecol. 1983;145:158-163.

17. D’Angelo LJ, Sokol RJ. Short- versus long-course prophylactic antibiotic treatment in cesarean section patients. Obstet Gynecol. 1980;55:583-586.

18. Jacobson JA, Hebertson R, Kasworm E. Comparison of ceforanide and cephalothin prophylaxis for vaginal hysterectomies. Antimicrob Agents Chemother. 1982;22:643-647.

19. Avorn J, Soumerai SB, Taylor W, et al. Reduction of incorrect antibiotic dosing through a structured educational order form. Arch Intern Med. 1988;148:1720-1724.

20. Gillings D, Makuc D, Siegel E. Analysis of interrupted time-series mortality trends: an example to evaluate regionalized perinatal care. Am J Public Health. 1981;71:38-46.

21. Safran C, Porter D, Lightfoot J, et al. ClinQuery: a system for online searching of data in a teaching hospital. Ann Intern Med. 1989;111:751-756.

22. Wallace RL, Major MC, Yonekura ML. The use of prophylactic antibiotics in patients undergoing emergency primary cesarean section. Am J Obstet Gynecol. 1983;147:533-536.

23. Hirschmann JV, Inui TS. Antimicrobial prophylaxis: a critique of recent trials. Rev Infect Dis. 1980;2:1-23.

24. Soumerai SB, Avorn J. Efficacy and cost-containment in hospital pharmacotherapy: state of the art and future directions. Milbank Mem Fund Quart. 1984;62:447-474.

25. Achong MR, Wood J, Theal HK, Goldberg R, Thompson DA. Changes in hospital antibiotic therapy after a quality-of-use study. Lancet. 1977;ii:1118-1122.

26. Soumerai SB, Avorn J. Principles of educational outreach ('academic detailing') to improve clinical decision making. JAMA. 1990;263:549555.

27. Lomas J, Anderson GM, Domnick-Pierre K, Vayada E, Enkin MW, Hannah WJ. Do practice guidelines guide practice? The effect of a consensus statement on the practice of physicians. $N$ Engl J Med. 1989;321:1306-1311.

28. Stross JK, Bole GG. Evaluation of a continuing education program in rheumatoid arthritis. Arthritis Rheum. 1980;23:846-849. 